\title{
The competencies needed for digital transformation
}

\author{
Patrick Fonseca, ISEG - University of Lisbon, Portugal, patrick.fcf@aln.iseg.ulisboa.pt \\ Winnie Ng Picoto, ISEG - University of Lisbon, Portugal, w.picoto@iseg.ulisboa.pt
}

\begin{abstract}
Due to advanced technologies, companies currently face massive changes in their work. The ability to connect with and to satisfy their customers through software-based experiences is even more important. This study contributes to the literature by helping companies rethink their strategies on the development of competencies to respond to the challenges of the current digital transformation. It further contributes by identifying the digital competencies, which are important in the companies' workplace environment of today. This study used a panel of 16 professionals to create an ordering rank according to the degree of importance of digital competencies. This ranking provides an updated overview of the challenge from the gap in digital competencies that has resulted from the digital transformation. We used the Delphi method to divide this process into two phases with two rounds. According to the results, the most important digital competencies are related with data analysis, use, and collaboration through digital technologies.
\end{abstract}

Keywords: Digital transformation, talent gap, digital competencies, Delphi method.

\section{Introduction}

Beyond our personal lives, technology is drastically influencing business sectors. The transformation of companies is no longer a question of 'what if', but rather a question of 'when it will happen'. The emergence of new digital technologies is forcing organizations to transform themselves through the digitalization of products, services, business processes, and innovative business models (Moroz, 2018). However, the number of possible applications of digital services and the types of software and their interaction with the user are so broad that it is necessary to consider professionals with the proper digital skills to use all the emergent digital tools in this new digital era. We define skills as the ability to do something well, and competencies as a set or bundle of skills that are needed to produce the necessary organizational outcomes (Johnson et al., 2008). Samuel (2016) reinforced this definition by stating that smart organizations have recognized that implementing digital technologies in the workplace goes beyond hardware or software as it involves changing behaviors as well as work practices highlighting the importance of people and their ability to use the technology to transform the organization.

Digital Transformation (DT) takes place when organizations embrace the potential of social learning in the design as well as the process of delivering contents, problem-solving, knowledge sharing, and user-generated content (Sousa \& Rocha, 2018). In light of this context, the main focus of this research is to contribute to DT by identifying the competencies required to rethink organizational strategies with different sets of skills and roles to facilitate Information Technology (IT) adoption and use. Therefore, this study aims to answer the following research questions: 
$\mathrm{RQ} 1$. What are the primary digital competencies for the digital transformation of the workplace?

RQ2. How do they rank in relative importance?

The primary goal of this study is to contribute to the discussion of an effective DT of companies based on the latest trends in competencies. We also intend to analyze and identify the experts' perceptions of what are the most important digital competencies for a DT to occur within a company. Therefore, we use Vuorikari's et al. (2016) DigComp conceptual reference model with its 21 competency descriptors divided into five competency areas: information and literacy, communication and collaboration, digital content creation, safety, as well as problem solving. We used the Delphi method with two phases and two rounds (Deng et al., 2013). We developed a questionnaire with the online tool SurveyMonkey that allows us to create rankings. We sent the survey by email to the participants. We adopt a Kendall $\mathrm{W}$ value of equal to [or higher than] 0.5 that Hasson et al. (2000) proposed for the level of consensus to compare the two rounds.

According to the results, the five most important digital competencies are: "(1) evaluating data, information, and digital content; (2) browsing, searching, and filtering data, information, and digital content; (3) interacting through digital technologies; (4) managing data, information, and digital content; and (5) collaborating through digital technologies" (Vuorikari et al., 2016, p. 8). The five top competencies obtained by this study are consistent with the competency area dimensions 1 and 2 of the European Digital Competence Framework for Citizens: information and data literacy and communication and collaboration respectively. Thus, the importance of these competencies is evident.

The remainder of this paper is organized as follows: First, it presents the background for this study by presenting the digital landscape. Then, it presents digital transformation followed by a literature review about the skills for digital transformation and the digital competence reference model. Third, we explain the method, fourth we present and discuss the results. Finally, we conclude the paper.

\section{Background}

\section{The Digital Landscape}

Mobile devices, smart devices, computers, and the Internet are now on our daily lives (Müller \& Hopf, 2017). According to Moroz (2018), the current development of civilization and the process of transition to the digital economy is irreversible. In order to transform a company and allow new channels to generate real value, it needs to rethink its actions integrating digital tools into its core. Therefore, knowing how to interact with the drivers of this transformation is important (Gardien et al., 2014). The intensive adoption of information and communication technologies has created DT (Moroz, 2018). The process of DT begins with a business evaluation strategy in a scenario dominated by uncertainties that require a focus on the challenges ahead. In fact, although some organizations are still thinking according to a specific paradigm to hold to their approach, society is indeed in a new era (Gardien et al., 2014). The focus on the application functionalities as the main metric for a successful technology is now shifting to a constantly evolving, user-focused experience and its opinions. This is a revolution that is fundamentally changing the way we live, 
work, and relate to one another is also transforming the way companies operate (Bourne, 2016). Furthermore, companies need to undergo a DT to survive and eventually thrive (Telegescu, 2018).

\section{Digital Transformation}

With the turn of the 20th century, societies in advanced industrial economies developed a shared aspiration to modernize their lives through the acquisition of products that fulfill functional needs, automated many aspects of people's lives and provided pride of ownership. (Gardien et al., 2014, p. 120)

According to Moroz (2018), digital transformation is not uniformly recognized and defined in the literature. However, industry views the phenomenon of DT as a disruptive change which has various potentials for companies (Müller \& Hopf, 2017). For example, Hanna (2016) defined it as "deep structural changes in the economy and society brought about by harnessing the full potential of the ICT revolution" (p. 27), while Herbert (2017) defined it as "a company's ability to react and successfully utilize new technologies and procedures - now and in the future" (p. 4).

As described by Transformação Digital (2017), the essence of DT consists of digitization, dematerialization, demonetization, democratization, and disruption. In light of the acute portent of disruption, DT is not just adopting digital technologies, it is about using and embedding them in the organizational processes, products or services. According to Telegescu (2018), the current society is in the middle of a new era of industrial revolution, but this time the output is not tangible, it's intangible - or digital. New digital services, from automation to the Internet of Things (IoT) from cloud services to shared applications, provide opportunities for efficiency and growth (Center for Creative Leadership, 2018). By understanding the connections between three main dimensions, human, technological, and organizational, 'small ideas can grow big' in a very short space of time.

As Müller and Hopf (2017) described, the horizontal as well as vertical integrations of business processes among and between companies represent the basis for the DT. Needless to say, DT goes far beyond marketing related activities. The MIT Center of Digital Business and Capgemini (2011) addressed this problem by describing DT as having three pillars: the operational process, the customer experience, and the business model.

Over the years, information systems and technologies have supported the automation of business processes in order to improve their efficiency (MIT Center of Digital Business \& Capgemini, 2011). For instance, Enterprise Resource Planning (ERP) systems have enabled significant efficiency and quality gains in core processes. Technology is at the center of the strategical definition that designs business processes of all organizational areas in which new technologies are extending the trend of gaining benefits beyond efficiency. Concepts such as agile methods or ubiquous working, anywhere and anytime, are widely used that aim at the automation for several activities in the intangible value chain: collecting, processing, using large data sets to reduce the costs and time of business processes (Moroz, 2018). But for these operations to be valuable, real changes must happen first in the mindset of the company (Telegescu, 2018).

The coronavirus pandemic and subsequent quarantine measures are drastically affecting individuals' lives as well as the world's economy. Consequently, it changes the way users and companies work, interact with technology, or consume digital content. According to Goldman (2017), in difficult times like the current one, organizations should invest on tools that can improve 
their workforce digital competencies such as collaborative systems, virtual meetings, or interactive communication applications. These tools mean also equipping each person in the organization with the skills and mindset that allow them to successfully adapt new tools such as Slack, Basecamp, or Google Drive to accomplish their work (Samuel, 2016). Along with the necessary digital infrastructure, digital competencies of the workforce are of the outmost importance to implement organizational changes to respond to this critical situation.

According to Müller and Hopf (2017), if companies, humans, and machines work together; the result is a better product through the use of the most appropriate interaction channel with a more efficient service. A deep understanding of the customer profile is important in order to be able to offer an improved customer experience. "The human being with his cognitive abilities is the key element for the digital transformation" (Müller \& Hopf, 2017, p. 1496).

From the economic standpoint, the use of information systems technologies improves organizational performance and support the creation of more profitable business models (Moroz, 2018). It is now necessary to think about the different channels that customers are on and how best to prospect them, identifying the tools workers can use to optimize their performance in order to accelerate productivity (Transformação Digital, 2017). In addition to the digital business model, there is also the possibility of creating new online businesses (Transformação Digital, 2017). Companies are introducing digital products that complement traditional ones (MIT Center of Digital Business \& Capgemini, 2011).

\section{Literature Review}

\section{Skills for the Digital Transformation}

Digital technologies are forcing companies to change their static processes, slowness, and lack of customer knowledge (Müller \& Hopf, 2017). However, technology is just one of the requirements for DT. The most important one is related to people with abilities and skills that allow companies to rethink their strategies in order to respond to the challenges of DT.

\section{New Trends in Skills Development}

Companies are perceiving new concepts about skills development as strategic management tools to cope with the current business environment (Kyllonen, 2013). Telegescu (2018) defined new technologies, such as Artificial Intelligence (AI), IoT, augmented virtual realities, quantum computing, blockchain technologies, as irreversibly and materially changing the business landscape at a fast pace. For the workplace, companies are likely ignoring digital skills and even the other competencies required to implement their DT because of their need to fulfill technical roles. This is a complex problem, partly due to the globalization and the accelerated rhythm of the above technologies, but also because they are increasingly demanding human resources with suitable skills to help companies overcome the apparent challenges of DT and to build a better user experience (Sousa \& Rocha, 2018).

Skills for DT are emerging in the market, and companies are integrating the impacts of new technologies into their organizations or people's lives. According to Goldman (2017), employees are not getting less tech-savvy, but rather that the market demands more of each and every one of 
them. Companies can enrich the roles of employees, generate higher quality, change their structure, increase flexibility, and decrease time to market of products. In fact, the word 'digital' is usually applied to refer to the company's IT investments, or its social media maturity, but now it has a wider meaning as it includes the organizational culture (Goldman, 2017).

\section{The Digital Talent Gaps}

While the literature references the top-level support for DT as a critical success factor, it is often not enough. According to a Chief Information Officer (CIO) Study on March 1, 2018, companies are facing difficulties to hire professionals with skills to develop user experiences taking into account the digital services. Also, according to Goldman (2017), the reskilling of the workforce will be a major issue in the next years. Daugherty (2018) wrote that companies require analysis on how to leverage people as well as technology in the context of DT. A survey of 753 employees and 501 executives conducted by Capgemini and LinkedIn pointed out that $55 \%$ of organizations acknowledge that the digital talent gap is widening (Buvat et al., 2017). However, in five years, we argue that we will not be worried about coders, but the lack of people with soft skills (Daugherty, 2018). We are short of people who can understand the human experience.

From the perspective of DT, the MIT Center of Digital Business and Capgemini (2011) argued that emerging technologies are another area where skills may be scarce within the organization. For instance, Fujitsu Future Insights (2018) argued that the biggest overall challenge is the lack of skilled staff. Even though seven years apart, both reports reinforce the importance of qualified skills in the organizational environment. Indeed, the emergence of digital technologies is forcing companies to transform, and this change has brought about new circumstances in which many companies struggle to cope. Additionally, the main challenges for a successful implementation of digital transformation are more related with the organization culture and human resources then with technology aspects (MIT Center of Digital Business \& Capgemini, 2011).

\section{Digital Competencies}

Although the word skill may suggest the concept is the same as competencies, they are different. Skills are the ability to do something well, or expertise, while Johnson et al (2008) described competencies as complex bundles of skills, accumulated knowledge that employees exercise through the organizational process that enables them to coordinate activities and make use of their assets. Aligned with the concept of digital competencies, Buvat et al. (2017) proposed a list of digital roles that DT activities have created within a company or the emergence of disruptive technologies. Furthermore, according to Boulton (2018), hiring enough full-stack developers, web managers, robotics specialists, and other roles required to facilitate DT remains a tall task for CIOs. However, the talent gap is not limited to technical skills as companies are also struggling to find and hire employees with competencies who can help build a better User Experience (UX) in this new digital era (Boulton, 2018). According to Schuchmann and Seufert (2015), the relevance of the companies' development capability also requires fostering the employees' self-organization for learning as well as for working terms to implement new organizational forms, leadership modes, and management systems. 


\section{The Digital Competence Reference Model}

The aim of this paper is to contribute to the understanding of the digital competencies that are important to a company in the context of DT. Although there is a growing interest in DT, the research has written little about digital competencies related to the workplace. Therefore, this study appears to be highly relevant. This study is based on the competencies that were identified by the European Digital Competence Framework for Citizens, also known as DigComp. This Digital Competence Framework for Citizens is composed of four dimensions: "areas identified to be part of the digital competence, competence descriptions and titles that are pertinent to each area, levels of proficiency for each competence and examples of the knowledge, skills and attitudes applicable to each competence" (Vuorikari et al., 2016, p. 6). This study focuses on the first and second dimensions of that framework. Those two dimensions compose the conceptual reference model.

The first competency area of the conceptual reference model relates to gathering information and data literacy. The second competency area aims at communicating and collaborating through digital technologies while being aware of cultural diversity (Vuorikari et al., 2016). The third competency area focuses on improving and integrating information while understanding how copyright can influence this process. Safety is the fourth competency area and reflects being aware of the impact of digital technologies and their use. The fifth competency area is the use of digital tools to innovate processes and products.

\section{Methodology}

\section{Delphi Method}

The research questions in this study are what are the primary digital competencies for the digital transformation of the workplace? and how do they rank in relative importance? Following the collection of key digital competencies based on the literature review, this research proposes a qualitative exploratory study and a methodological approach of Delphi rankings (Schmidt, 1997). The Delphi method is based on rounds of questions and group decision-making through iterative feedback in which the opinions of a panel of experts are examined to reach a consensus (Deng et al., 2013). In this sense, the primary goal of the Delphi method is a consistency of opinion from a group of experts regarding an area of interest or inquiry (Hasson et al., 2000). Currently, the Delphi method is widely applied in different fields of research such as education, engineering, health care, among others (Deng et al., 2013). In this case, the use of the Delphi method enables participants to freely express their opinions on these topics without undue social pressure and to refine their views in light of the progress of the group's work from round to round.

The classification of the Delphi method does not have a specific work scheme, but Marques and Freitas (2018) proposd dividing the method into three distinct phases (See Appendix A). The first phase focuses on the selection of the group of experts and the construction of Questionnaire 1. First contact with the experts is an invitation to participate in the research. The second contact is their submission of Questionnaire 1 and their responses. The second phase consist of a qualitative and quantitative analyses of the responses. First, Questionnaire 2 is constructed and launched. Second, the responses are received and analyzed. In the third phase, the final report is written to end the process. 
To measure the consensus, we used the Kendall W coefficient of agreement. This coefficient indicates realistically if the group reached consensus, whether consensus increased or decreased between rounds, and the relative strength of consensus. This method is popular largely because of the simplicity of its application. Schmidt (1997) proposed the following interpretation of the values of Kendall W:

Table 1. Kendall W Values (Schmidt, 1997, p. 767)

\begin{tabular}{|l|l|c|}
\hline $\mathbf{W}$ & \multicolumn{1}{|c|}{ Interpretation } & Confidence in Ranks \\
\hline 0.1 & Very weak agreement & None \\
\hline 0.2 & Weak agreement & Low \\
\hline 0.3 & Moderate agreement & Fair \\
\hline 0.4 & Strong agreement & High \\
\hline 0.5 & Unusually strong agreement & Very high \\
\hline
\end{tabular}

After each round, whether a new round can garner greater consensus needs to be considered. However, accounting for the feasibility and potential gain of a new round is essential. When Kendall W is small, this decision is easier to make. However, when there is moderate consensus it becomes more difficult to weigh the advantages and disadvantages. To evaluate the correlation of opinions between rounds, the correlation coefficient of the ranking order of the Spearman rho is used since this coefficient emphasizes the magnitude of difference between the positions of the items in the ranking (Schmidt, 1997). The values of this test vary between -1 and 1 . The closer to 1 , the greater the convergence of opinions between rounds. On the other hand, -1 indicates that there is no relation in the ordinations between rounds (Kalaian \& Kasim, 2012).

\section{Results}

\section{Delphi First Phase}

The first phase focuses on gathering information about the subject matter experts and selecting the list items to formulate the questionnaire (Marques \& Freitas, 2018). According to Okoli and Pawloski (2004), the ideal size of the panel is 10 to 18 people with a maximum of four panels at one time. The aim is to choose professionals who were knowledgeable about the theme under study. The identification of these professionals was based on a search for professionals currently working with DT that were on LinkedIn. The panel consists of 16 total individuals: eight professionals assigned to DT projects and activities, four business intelligence consultants, two project managers, one mobile specialist developer, and a senior software developer. Regarding the characterization of the panel according to gender, three were woman and 13 were men. The experts were located as follows: right in Portugal, three in France, two in Sweden, one in the UK, one in the Netherlands, and one in Brazil. Table 2 provides the breakdown of the 16 participants' experience level. 
Table 2. Average years of experience in the IS/IT sector $(\mathrm{N}=16)$

\begin{tabular}{|l|l|}
\hline Answer Choices & Responses \\
\hline $1-5$ years & $45.45 \%$ \\
\hline $6-10$ years & $9.09 \%$ \\
\hline $11-15$ years & $36.36 \%$ \\
\hline $16-20$ years & $0.00 \%$ \\
\hline More than 20 years & $9.09 \%$ \\
\hline
\end{tabular}

Thus, the characterization of the panel according to the types of IS projects in which they were already involved is presented in Figure 1.

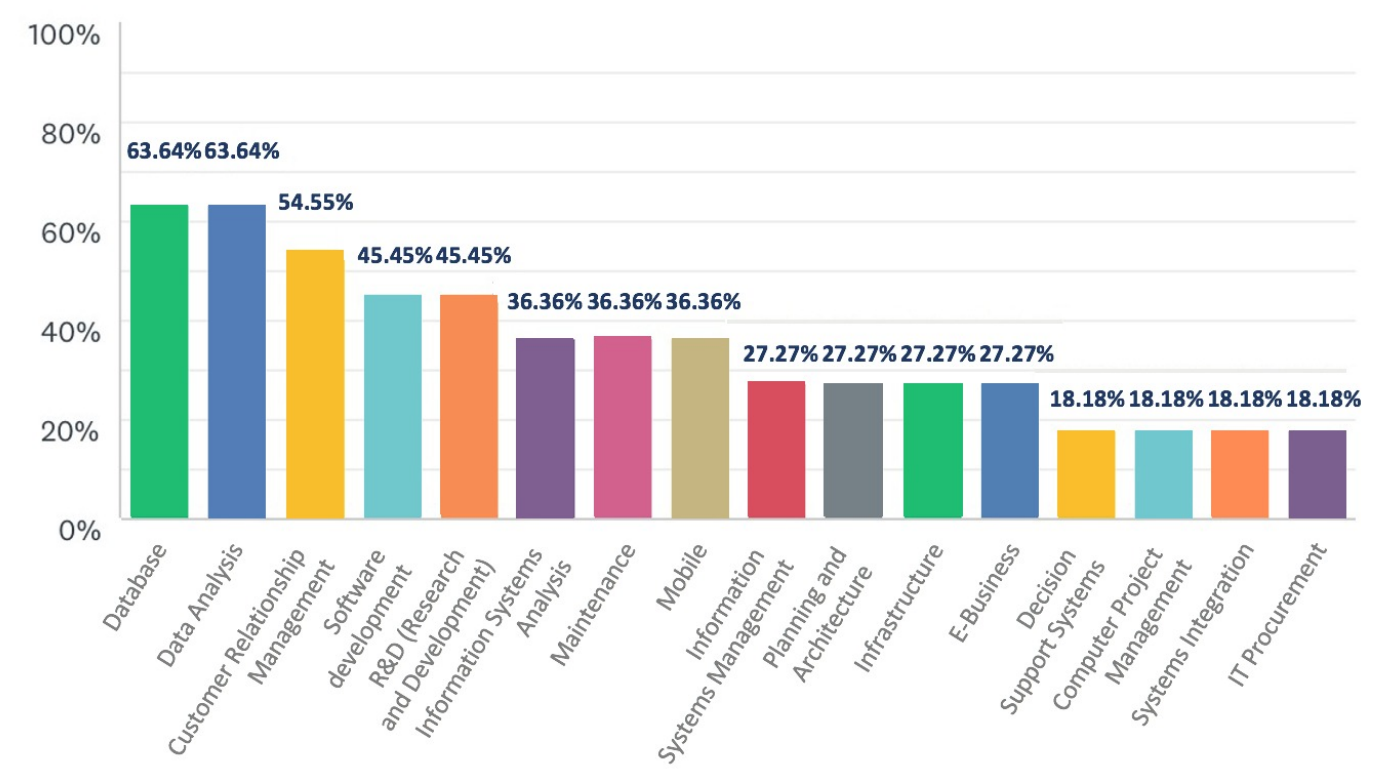

Figure 1. IS Projects of the Experts

Schmidt (1997) indicated a list with a maximum of 10 to 20 items for this phase. Therefore, we chose the list of 21 competencies without specifying their competency area because it appeared to be a satisfactory amount, according to three important aspects of the Delphi rankings identified by Hasson et al. (2000): "the time available for the study should be considered; whether the researcher has indicated the Delphi sequence with one broad question or with a list of questions; and consideration of levels of experts' fatigue" (p. 1011). We decided to perform one to two rounds at most because according to Hasson et al. (2000), this is the ideal range. In turn, for each round, the target response rate should be at least $70 \%$ so that the study is relevant. 
In this phase, we used SurveyMonkey to create the rankings (See Appendix B). The expert panel was invited to rank the 21 competencies with the first being the most important factor and the $21 \mathrm{st}$ being the least important. At this point, the competencies were randomly listed in the survey that is different from the order presented by Vuorikari et al. (2016) in the DigComp framework. Further, the order of the competencies was the same for each panel member as the SurveyMonkey link was the same for each member.

The first round began on July 23, 2019 and ended on July 30, 2019. The total response rate was $73 \%$ for Wuestionnaire 1 that had a total of five questions of which one was not mandatory. This phase also used the GNU PSPP for data processing. It is similar with a few exceptions, but for this study, the tool is appropriate. For the input of the data in this tool, the competencies were ordered alphabetically. The Kendall W value obtained is 0.280 which indicates weak agreement. The following table shows the results:

Table 3. Ordering of Competences After the First Round

\begin{tabular}{|c|c|c|}
\hline Ranking & Competencies & Score \\
\hline $1^{\mathrm{o}}$ & Evaluating data, information and digital content & 25.07 \\
\hline $2^{\circ}$ & Browsing, searching and filtering data, information and digital content & 24.33 \\
\hline $3^{\circ}$ & Interacting through digital technologies & 23.20 \\
\hline $4^{\circ}$ & Managing data, information and digital content & 22.73 \\
\hline $5^{\circ}$ & Collaborating through digital technologies & 21.73 \\
\hline $6^{\circ}$ & Sharing through digital technologies & 20.33 \\
\hline $7^{\circ}$ & Identifying needs and technological responses & 20.27 \\
\hline $8^{\circ}$ & Protecting personal data and privacy & 20.20 \\
\hline $9^{\circ}$ & Creatively using digital technologies & 20.20 \\
\hline $10^{\circ}$ & Managing digital identity & 19.07 \\
\hline $11^{\circ}$ & Solving technical problems & 19.00 \\
\hline $12^{\circ}$ & Identifying digital competence gaps & 18.60 \\
\hline $13^{\circ}$ & Engaging in citizenship through digital technologies & 18.40 \\
\hline $14^{\circ}$ & Programming & 17.87 \\
\hline $15^{\circ}$ & Protecting health and well-being & 17.53 \\
\hline $16^{\circ}$ & Developing digital content & 17.00 \\
\hline $17^{\circ}$ & Protecting devices & 15.67 \\
\hline $18^{\circ}$ & Integrating and re-elaborating digital content & 15.60 \\
\hline $19^{\circ}$ & Protecting the environment & 14.67 \\
\hline $20^{\circ}$ & Netiquette & 13.80 \\
\hline $21^{\circ}$ & Copyright and licenses & 13.73 \\
\hline
\end{tabular}

The statistical data from the PSPP shows a Chi-square $\left(\chi^{2}\right)$ of 83.67 and an Asymp. Sig. (2-sided) for the Pearson Chi-square $\left(\chi^{2}\right)$ of zero. In order to complement the richness of the study, we asked two more questions of the experts in this round related to the competencies they had just ranked. And those questions were: if there is another competency that was not in the previous list, what 
would it be?; describe an important project you have worked on, and if you had applied any of the competencies just ranked?

For the first question, the experts pointed to competencies like: link between AI and common technological assets; digital strategy; digital planning of activities throughout the team; data analysis (business intelligence); culture, artificial intelligence, communication, and prototyping. For the second, they responded that from the competencies presented to them, they had applied many. For instance, in a "project on Health Inequalities, I applied several of the mentioned competencies". Related to databases and Business Intelligence (BI), an expert answered that "on all my BI projects I've applied many of those competencies.". Another answered that "we've been through several database related projects where a strong sense of data analysis and data manipulation was crucial to the success of the projects".

According to an expert who provided more details, he said that "I've worked in an important project to collect user data following EU, US and Brazilian rules of personal data protection to create reports to guide the development of new products and support planning team to create an accurate forecast of sell-in/sell-out. To develop this project, I applied or would apply following competencies: 1- Evaluating data, information and digital content 2-Protecting personal data and privacy 3- Managing data, information and digital content 4-Browsing, searching and filtering data, information and digital content". Further, three of the four competencies mentioned by the expert were in the top 5 that resulted from the first-round rankings.

From the perspective of new technologies listed by the experts in the previous question, the competencies were applied in "preventive maintenance with drones, computer vision and image processing with Machine Learning algorithms". In a "cloud website for registering tobacco selling merchants and suppliers". Finally, two experts drew attention to the fact that "I'm applying most of them in a current project, on a digital transformation program. Don't forget Culture and People. Digital Transformation is not about Technology. Check some HBR posts and articles". In "any project I worked on, I used the first competency, being user first and understanding the needs and the tech response! All the rest is so generic and depends on your role".

\section{Delphi Second Phase}

Given the value of the Kendall W in the first round, we decided to run another round. The second round began on August 12, 2019 and ended on August 18, 2019. We shared the results of the previous round with all experts and indicated that the aim of running another round was to increase the consensus among the experts. In the second survey, the order of the competencies was not random but instead was in the order that resulted from the first round. The response rate was 100\% with only one mandatory question. Further, the experts who participated in the second round were the same from the first round. The value of the Kendall $\mathrm{W}$ for the second round was 0.910 which indicated an unusually strong agreement. The Spearman rho value was 0.997 which indicated a high convergence of opinions between rounds among all experts in the panel. The PSPP program only provided a bivariate (Pearson) correlation, so the value of the Spearman rho was calculated in Excel to compare the results. The outputs show a Pearson correlation of 0.97 and a Spearman correlation (CORREL function) of 0.997 , which is the same value as the Spearman correlation from the traditional statistical formula. 
After this round, we decided to terminate the data collection. This decision took into account three factors in the literature that justify stopping the rounds: (1) Hasson et al. (2000) indicated that two or three rounds are preferred; (2) a strong consensus is one statistical criterion to stop, which occurred after analyzing round two results (Schmidt, 1997); (3) Kalaian and Kasim (2012) stated that if the value of the Spearman rho correlation is close to one, then it indicates that there is already a strong convergence in opinion that will make it difficult to increase the degree of agreement. Table 4 shows the final ranking of competences.

Table 4. Ordering of competences after the second round

\begin{tabular}{|l|l|c|}
\hline Ranking & Competencies & Score \\
\hline $1^{\circ}$ & Evaluating data, information and digital content & 19.81 \\
\hline $2^{\circ}$ & Browsing, searching and filtering data, information and digital content & 19.06 \\
\hline $3^{\circ}$ & Interacting through digital technologies & 18.50 \\
\hline $4^{\mathrm{o}}$ & Managing data, information and digital content & 18.00 \\
\hline $5^{\circ}$ & Collaborating through digital technologies & 17.06 \\
\hline $6^{\circ}$ & Sharing through digital technologies & 15.44 \\
\hline $7^{\circ}$ & Protecting personal data and privacy & 15.19 \\
\hline $8^{\circ}$ & Identifying needs and technological responses & 14.94 \\
\hline $9^{\circ}$ & Creatively using digital technologies & 13.44 \\
\hline $10^{\circ}$ & Managing digital identity & 12.69 \\
\hline $11^{\circ}$ & Solving technical problems & 10.50 \\
\hline $12^{\circ}$ & Identifying digital competence gaps & 9.94 \\
\hline $13^{\circ}$ & Engaging in citizenship through digital technologies & 8.94 \\
\hline $14^{\circ}$ & Programming & 7.19 \\
\hline $15^{\circ}$ & Protecting health and well-being & 7.06 \\
\hline $16^{\circ}$ & Developing digital content & 6.31 \\
\hline $17^{\circ}$ & Protecting devices & 5.38 \\
\hline $18^{\circ}$ & Integrating and re-elaborating digital content & 4.06 \\
\hline $19^{\circ}$ & Protecting the environment & 3.94 \\
\hline $20^{\circ}$ & Copyright and licenses & 1.88 \\
\hline $21^{\circ}$ & Netiquette & 1.69 \\
\hline
\end{tabular}

\section{Discussion of Research Findings}

After data collection, we were able to verify that the panel formed by professionals with knowledge of the subject under study registered an unusually strong agreement in the opinions regarding the ranking. Furthermore, only one expert agreed with the full order that resulted from the first-round scores (from all 16 interviewed). Given these values of agreement, the study may give important support to DT. As European Commission (2018) stated, "most companies face the strategic challenge of upgrading quickly both specific ICT skills and the transversal digital competence of their workforce in the DT" (p. 57). Also, noteworthy is the strong convergence of opinions between the two rounds. In fact, we observed that there were no changes in the positions of the first five competencies, only four competencies from the total changed after the second round. These 
changes could happen because the experts have checked the order of the competencies from the first round with their scores and have re-thought their first ideas that changed their perceptions of the most important competencies.

Our results show the importance of evaluating data, information, and digital content. This competency was in first place in both rounds. In fact, to Moroz (2018), this new digital era requires citizens to gain a new level of skills appropriate for the current context, which can be divided into:

Skills allowing the user to determine when information is needed and to search, evaluate and use information from various sources; and skills in using a computer and other electronic devices, using the Internet and various types of applications and software, as well as creating digital content. (p.70)

The second position in both rounds was held by the competency of browsing, searching, filtering data, information, and digital content. According to Vuorikari et al. (2016), this competency is linked to "searching for data, information, and content in digital environments to access them and to navigate between them" (p. 14). Telegescu (2018) supported this view when describing that "IoT technologies can increase workplace productivity by 'filtering' out relevant and personalized information, from sensors relevant only to the recipient of the information, thus contributing to tailored data streams" (p. 961). The competency of interacting through digital technologies was third in both rounds. MIT Center of Digital Business and Capgemini (2011) suggested that this will help develop new ways of interacting as well as selling products to the customer via new technologies and self-service areas. The fourth position was occupied by the competency of managing data, information, and digital content. A Digital Future Executive Summary from Dell Technologies in 2016 argued that businesses are starting to make purposeful, data-driven technology choices. Information technology influences the way employees do their work tasks in terms of the flexibility of the workplace and how those tasks are performed (Telegescu, 2018). In the current COVID 19 crisis, this aspect has proved been of a particularly relevant to support the virtual workforce in many organizations worldwide. Last place of the top five is collaborating through digital technologies. Moroz (2018) indicated that immediate and very cheap communication as well as exchange of knowledge and ideas are the main factors triggering the DT. The Center for Creative Leadership (2018) also supported the idea that DT benefits from improved usability and networked connectivity. According to the same study, 39\% of the participants have implemented digital tools to enhance the efficiency of employees and to foster the collaboration among them. This collaboration networks are important to share and create knowledge in the organization.

After the top five, the four competencies that changed after the second round are also important to be analyzed. The first one was held by protecting personal data and privacy. This competency went up one position. The Digital Future Executive Summary from Dell Technologies in 2016 stated that the top barriers to the progress of DT were concerns about data privacy and security. To reinforce this idea, a 2017 survey developed by Capgemini and LinkedIn of 753 employees plus 501 executives found that of the top 10 digital roles of the next two to three years, information security and privacy were at the top (Buvat et al., 2017).

The competency of identifying needs along with the technological responses came down one position to eighth in the final ranking. In the competency area dimension of problem solving, has 
become more important by the addition of new tools for information visualization and larger amounts of available data. As well, "important updates relate to accessibility and social inclusion" (Vuorikari et al., 2016, p. 11).

Copyright, licenses and netiquette were the other two competencies that changed after the second round. The copyright and licenses went up one position, while netiquette in turn went down a position in the standings. However, both competencies are less important in the scheme of things as they are 20th and 21st respectively.

\section{Conclusion}

Although DT is a buzzword that translates the path of transformation to embrace the emerging digital technologies into the business processes, products, services and customer experiences, the technology by itself is not going to provide the solution. This study aimed to identify and rank according to their degree of importance, the digital competencies which are primary in a company's workplace today. The main motivation in choosing this theme is the growth of the phenomenon of DT and the accelerated rhythm of new technologies. Additionally, the topic of digital competencies is still little studied. In fact, according to Moroz (2018), the knowledge on when and how to launch initiatives or the idea that new digital skills are needed is not clear for companies. In addition, the importance of digital competencies is highlighted by this coronavirus pandemic during which governments have forced people to stay home and work digitally while many companies had to change their business processes or even business models to survive this global crisis. Companies with higher levels of digital maturity and with more developed digital competencies have been better prepared to quickly respond to this crisis: in the first phase more urgently to respond to the emergency situation with focus on the importance of knowledge sharing. In a second phase, building on the knowledge gathered from the first phase and by analyzing the opportunities, be able to redesign the strategy to account for the increasingly important technological component.

This empirical study shows that the ordering of the five competencies considered as the most important presented a great coherence through Spearman's correlation coefficient since they occupied exactly the same places in both rounds. In this case, these top five competencies are: (1) evaluating data, information, digital content; (2) browsing, searching, filtering data, information, and digital content; (3) interacting through digital technologies; (4) managing data, information and digital content; and (5) collaborating through digital technologies. Thus, this study reflects the view of the Vuorikari et al. (2016) who claimed that "the key set of competencies needed for personal development, social inclusion, active citizenship, and employment" is knowledge important to any job function (p. 2). Another strategic concern is to adapt processes and organizational structures to meet the changing demands while being able to derive value from change. Companies and decision-makers need to address considerable challenges if they are to capture the full potential of digital competencies.

The major limitation of this study was the number of experts willing to help answering the research questionnaire, which directly influenced the fact that only one panel could be constructed and not others at the same time. This number may reflect not so well-founded opinions present in the panel about a subject still little studied. While more experts would allow other panels to run in parallel, 
responses could be compared not only between experts but also between different panels. Panel fatigue relative to the study was also taken into account. This fatigue was reflected by the increase in reminders sent in the second round that requested panel participation again in the survey. However, this study may provide a basis for workers as well as for future research. It would be interesting to understand and compare the differences between the digital competencies that are most important in the workplace environment to extract value from DT to derive value from structured data.

From the results obtained, it could still be beneficial to dive more deeply into dimensions 3 and 4 of the European Digital Competence Framework for Citizens, as well as trying to develop a new framework with the aim of ensuring that the digital competencies identified in the study are realized and which metrics to measure success. Especially when it comes to SMEs where resources are not always available, a framework could streamline processes by putting in place effective results already studied. Finally, it would be important to understand how the DT is being approached in Portugal and to understand if the digital competencies present in this study differ greatly from those that the reality of Portuguese organizations identifies as being the most important to extract value from DT.

\section{References}

Boulton, C. (2018, March 1). 8 essential roles for a successful digital transformation. CIO. https://www.cio.com/article/3258767/digital-transformation/8-essential-roles-for-asuccessful-digital-transformation.html

Bourne, V. (2016). Embracing a digital future: Transforming to leap ahead. Dell Technologies.

Buvat, J., Slatter, M., Pasquet, L., Crummenerl, C., Puttur, K. R., \& As, V. J. (2017). The digital talent gap: Are companies doing enough? Capgemini \& LinkedIn.

Center for Creative Leadership. (2018). Digital transformation readiness survey summary. https://www.ccl.org/wp-content/uploads/2018/04/Digital-Transformation-SurveyReport.pdf

Daugherty, R. P., \& Wilson, H. J. (2018). Human + machine: Reimagining work in the age of AI. Harvard Business Review Press.

Deng, T., Keil, M., \& Lee, H. K. (2013). Understanding the most critical skills for managing IT projects: A Delphi study of IT project managers. Information \& Management, 50(7), 398414. https://dx.doi.org./10.1016/j.im.2013.05.005

European Commission. (2018). DigComp into action: Get inspired, make it happen. A user guide to the European Digital Competence Framework. Luxembourg: Office for Official Publications of the European Communities.

Fujitsu Future Insights. (2018). Global digital transformation survey report. https://www.fujitsu.com/global/vision/insights/survey2/ 
Gardien, P., Djajadiningrat, J. P., Hummels, C. C. M., \& Brombacher, A. C. (2014). Changing your hammer: The implications of paradigmatic innovation for design practice. International Journal of Design, 8(2), 119-139.

Goldman G. (2017). Nearly half of companies say they don't have the digital skills they need. Harvard Business School Publishing.

Hanna, N. K. (2016). Mastering digital transformation: Towards a smarter society, economy, city and nation. Emerald Group Publishing.

Hasson, F., Keeney, S., \& McKenna, H. (2000). Research guidelines for the Delphi survey technique. Journal of Advanced Nursing, 32(4), 1008-1015.

Herbert, L. (2017). Digital transformation: Build your organization's future for the innovation age. Bloomsbury Publishing.

Johnson, G., Scholes, K., \& Whittington, R. (2008). Exploring corporate strategy: Text and cases. (8th ed.). Prentice Hall.

Kalaian, S. A., \& Kasim, R. M. (2012). Terminating sequential Delphi survey data collection. Practical Assessment, Research \& Evaluation, 17(5), 1-9.

Kyllonen, P.C. (2013). Soft skills for the workplace. Change: The Magazine of Higher Learning, 45(6), 16-23. https://doi.org/10.1080/00091383.2013.841516

Marques, Joana Brás Varanda, \& Freitas, Denise de. (2018). Método DELPHI: caracterização e potencialidades na pesquisa em Educação. Pro-Posições, 29(2), 389-415. https://dx.doi.org/10.1590/1980-6248-2015-0140

MIT Center for Digital Business \& Capgemini. (2011). Digital Transformation: a roadmap for billion-dollar organizations. Capgemini Consulting. https:/www.capgemini.com/frfr/wp-content/uploads/sites/2/2017/07/Digital Transformation_A_RoadMap for Billion-Dollar_Organizations.pdf

Moroz, M. (2018). Acceleration of digital transformation as a result of launching programs financed from public funds: Assessment of the implementation of the operational program digital Poland. Foundations of Management, 10(1), 59-74. https://doi.org/10.2478/fman-2018-0006

Müller, E. \& Hopf, H. (2017). Competence center for the digital transformation in small and medium-sized enterprises. Procedia Manufacturing, 11, 1495-1500. https://doi.org/10.1016/j.promfg.2017.07.281

Okoli, C. \& Pawlowski, S. D. (2004). The Delphi method as a research tool: an example, design considerations and applications. Information \& Management, 42(1), 15-29. https://doi.org/10.1016/j.im.2003.11.002

Samuel, A. (2016). The soft skills of great digital organizations. Harvard Business School Publishing.

Schmidt, R. C. (1997). Managing Delphi surveys using nonparametric statistical techniques. Decision Sciences, 28(3), 763-774. https://doi.org/10.1111/j.1540-5915.1997.tb01330.x 
Schumann, D., Seufert, S. (2015). Corporate learning in times of digital transformation: A conceptual framework and service portfolio for the learning function in banking organisations. Semantic Scholar, 8(1), 31-39. http://dx.doi.org/10.3991/ijac.v8i1.4440

Sousa, M.J. \& Rocha, Á. (2018). Digital learning: Developing skills for digital transformation of organizations. Future Generation Computer Systems, 91, 327-334. https://doi.org/10.1016/j.future.2018.08.048

Telegescu, T. (2018). IT in the workspace - The need for digital transformation. Proceedings of the International Conference on Business Excellence, 12(1), 952-965. https://doi.org/10.2478/picbe-2018-0085

Transformação Digital. (2017). O que é transformação digital? https://transformacaodigital.com/o-que-e-transformacao-digital/

Vuorikari, R., Punie, Y., Carretero Gomez S., \& Van den Brande, G. (2016). DigComp 2.0: The digital competence framework for citizens. Update Phase 1: The Conceptual Reference Model, Luxembourg Publication Office of the European Union, 1-40.

\section{Authors' Biographies}

Patrick Fonseca, MSc. is a Master Data Management (MDM) \& Data Governance Consultant on MDM solutions. He specializes in data management, data governance, and software development. He has a Master of Science degree in Information Systems Management from ISEG - Lisbon School of Economics and Management. He also holds a Bachelor's degree in Information Systems from Mackenzie University, with an emphasis in Business Management: Focused on

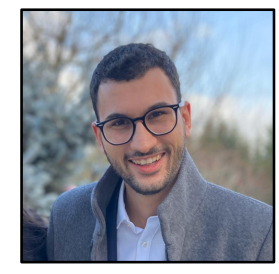
Corporate Systems. He has worked in the technology industry for 8 years, acting in different countries as Brazil, South Korea, Portugal, and France, holding several positions including software analyst on mobile area, Java/EBX5 developer, consultant, and programmer.

Winnie Ng Picoto, Ph.D. is Associate Professor of Information Systems and Operations Management at ISEG, Lisbon School of Economics \& Management, at the University of Lisbon. She holds a BA in industrial engineering and management from the Instituto Superior Técnico, a MIS from ISEG and a PhD in management from the Technical University of Lisbon. She is a member of the Advance Research Center. Her previous work experience includes information

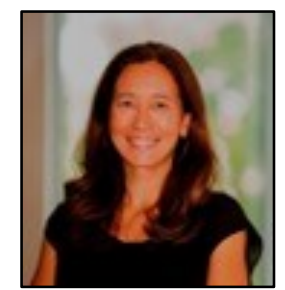
systems consulting. Her current research interests include the use of innovative IS, IT value, big data and emerging technologies. Her work has been published in journals such as European Journal of Information Systems, Journal of the Association of Information Systems, Journal of Business Research, Industrial Management and Data Systems, and Journal of Organizational Computing and Electronic Commerce. 


\section{Appendix A - Generic Scheme of Delphi Implementation Method with Three Rounds}

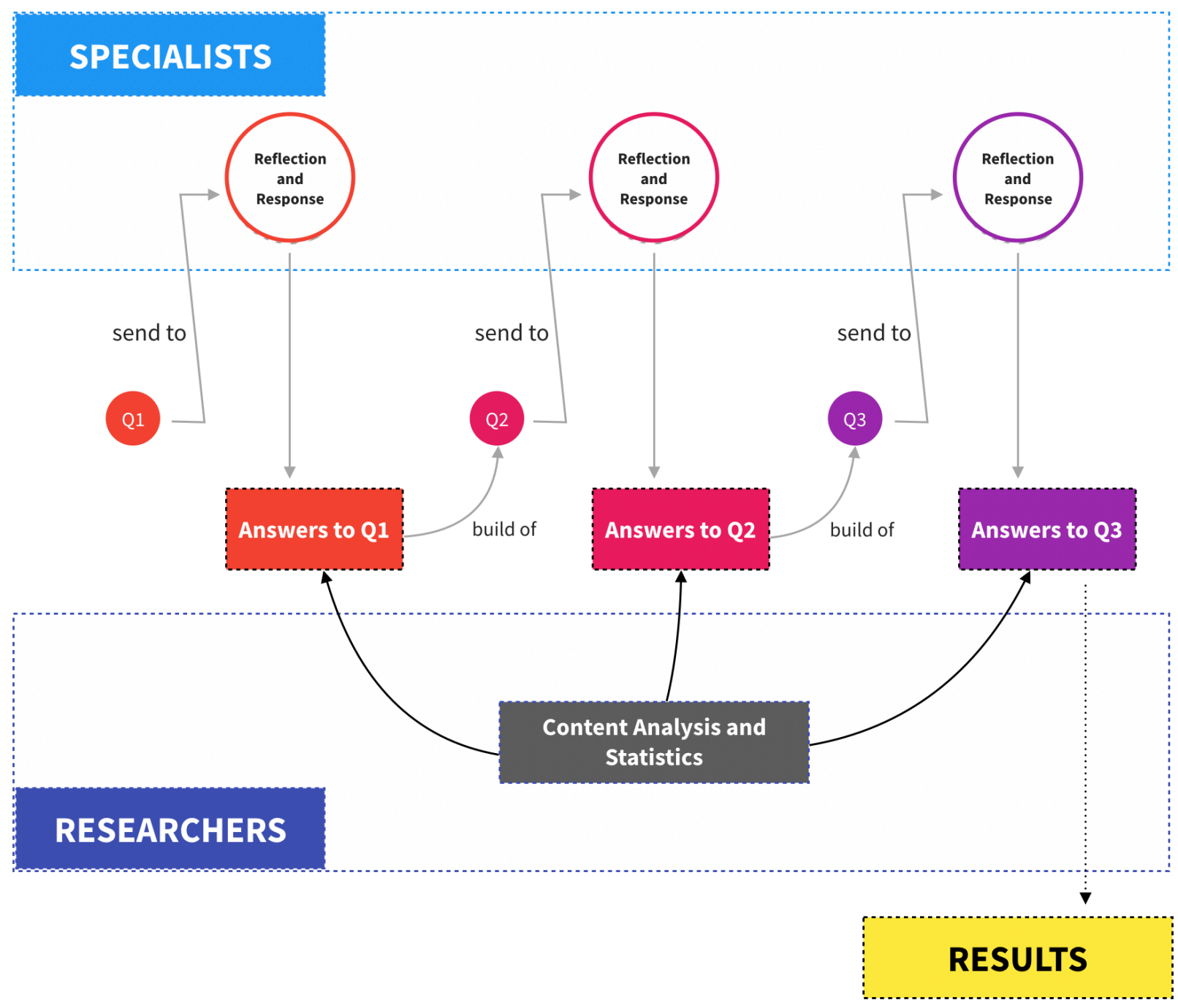




\section{Appendix B - The Survey Instrument}

\begin{tabular}{|c|c|c|}
\hline$\equiv$ & 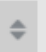 & Managing data, information and digital content \\
\hline$\equiv$ & 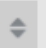 & Sharing through digital technologies \\
\hline$\equiv$ & 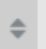 & Engaging in citizenship through digital technologies \\
\hline$\equiv$ & 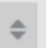 & Netiquette \\
\hline$\equiv$ & 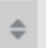 & Developing digital content \\
\hline$\equiv$ & 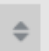 & Integrating and re-elaborating digital content \\
\hline$\equiv$ & 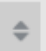 & Copyright and licenses \\
\hline$\equiv$ & 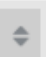 & Protecting devices \\
\hline$\equiv$ & $\Leftrightarrow$ & Protecting personal data and privacy \\
\hline$\equiv$ & 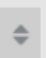 & Protecting the environment \\
\hline$\equiv$ & 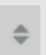 & Identifying needs and technological responses \\
\hline$\equiv$ & 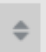 & Creatively using digital technologies \\
\hline$\equiv$ & 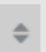 & Identifying digital competence gaps \\
\hline$\equiv$ & 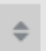 & Evaluating data, information and digital content \\
\hline$\equiv$ & 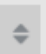 & Interacting through digital technologies \\
\hline$\equiv$ & 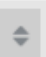 & Programming \\
\hline$\equiv$ & $\rightarrow$ & Collaborating through digital technologies \\
\hline$\equiv$ & 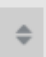 & Protecting health and well-being \\
\hline$\equiv$ & 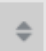 & Solving technical problems \\
\hline$\equiv$ & 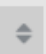 & Managing digital identity \\
\hline$\equiv$ & 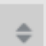 & Browsing, searching and filtering data, information and digital content \\
\hline
\end{tabular}

